(2) Open Access Full Text Article

\title{
Comparative efficacy of pitavastatin and simvastatin in patients with hypercholesterolemia: a meta- analysis of randomized controlled clinical trials
}

This article was published in the following Dove Press journal:

Drug Design, Development and Therapy

3I March 2015

Number of times this article has been viewed

\author{
Ning $\mathrm{Ma}^{1,2}$ \\ Lianqun Cui' \\ 'Department of Cardiology, \\ Shandong Provincial Hospital, \\ Shandong University, ${ }^{2}$ Department of \\ Cardiology, Heze Municipal Hospital, \\ Heze, Shandong, People's Republic of \\ China
}

Background: Simvastatin is a statin used to lower low-density lipoprotein cholesterol, but has limitations in patients on complicated regimens due to concerns about drug-drug interactions. Pitavastatin is a newly developed statin with limited drug-drug interactions. We conducted a meta-analysis to compare the clinical efficacy of simvastatin and pitavastatin in the control of hypercholesterolemia.

Methods: Randomized clinical trials comparing the efficacy of pitavastatin and simvastatin were identified by searching PubMed (2000-2014) and EMBASE (2000-2014). The primary outcome subjected to meta-analysis was percent change in low-density lipoprotein cholesterol compared with baseline.

Results: Four clinical trials were selected for meta-analysis. A total of 908 patients treated with pitavastatin ( 2 or $4 \mathrm{mg} /$ day) and 381 patients treated with simvastatin ( 20 or $40 \mathrm{mg} /$ day) were included in the final statistical analysis. No statistically significant difference was identified between treatment with pitavastatin $4 \mathrm{mg}$ /day and treatment with simvastatin $40 \mathrm{mg}$ /day for 12 weeks (mean difference $-0.66 ; 95 \%$ confidence interval $-2.92,1.61 ; P=0.57$ ). Similarly, no statistically significant difference was observed between pitavastatin $2 \mathrm{mg}$ /day and simvastatin $20 \mathrm{mg}$ /day for 4 weeks (mean difference $-2.19 ; 95 \%$ confidence interval $-0.11,4.49 ; P=0.06$ ). Treatment with pitavastatin was noninferior to simvastatin in all of the secondary outcomes and the safety profile was similar between the two statins.

Conclusion: Pitavastatin is noninferior to simvastatin in lowering low-density lipoprotein cholesterol.

Keywords: pitavastatin, simvastatin, hypercholesterolemia, meta-analysis

\section{Introduction}

Coronary heart disease (CHD) remains a leading cause of mortality and morbidity worldwide. ${ }^{1}$ One of the major risk factors for $\mathrm{CHD}$ is atherogenic dyslipidemia, especially primary hypercholesterolemia. ${ }^{2}$ Currently, statins are the most effective drugs for lowering low-density lipoprotein (LDL) cholesterol and control of hypercholesterolemia. ${ }^{3,4}$ However, there is a high frequency of statin treatment withdrawal in CHD patients on complicated regimens, most likely resulting from adverse drug-drug interactions. ${ }^{5}$ Therefore, efforts are ongoing to develop new statins with high potency, low drug-drug interaction, and long-term safety. Pitavastatin $\left(\right.$ Livalo $\left.{ }^{\circledR}\right)$ is a newly developed statin that is gaining popularity in the treatment of primary hypercholesterolemia. ${ }^{6,7}$ An attractive feature of pitavastatin is its selective uptake by hepatocytes and minimal metabolism by cytochrome P450 enzymes, thereby reducing the potential interaction with other drugs metabolized by these enzymes. ${ }^{8}$ Randomized controlled clinical trials
Correspondence: Lianqun Cui Department of Cardiology, Shandong Provincial Hospital, Shandong University, 324 Jingwu Weiqi Road, Jinan 25002I, People's Republic of China

Tel +86 531 69777915

Fax +86 53I 87902348

Email lianquncui0I@163.com 
demonstrated that pitavastatin was noninferior to currently used statins such as simvastatin and atorvastatin in terms of lowering LDL cholesterol levels. ${ }^{9-15}$ To provide an accurate insight in the clinical efficacy of pitavastatin, we performed a meta-analysis of four controlled clinical trials to compare the efficacy of pitavastatin and simvastatin in patients with hypercholesterolemia. ${ }^{9-13}$

\section{Materials and methods Database and search strategy}

We searched the PubMed and EMBASE databases from 2000 to April 2014 for relevant studies. Search terms used for PubMed were: ("pitavastatin"[Supplementary Concept] OR “pitavastatin"[All Fields]) AND "simvastatin"[MeSH Terms] OR “simvastatin”[All Fields]) AND ("clinical trials as topic"[MeSH Terms] OR ("clinical"[All Fields] AND "trials"[All Fields] AND "topic"[All Fields]) OR “clinical trials as topic"[All Fields] OR "trial"[All Fields]). Search terms used for EMBASE were: "pitavastatin”/exp/mj and [randomized controlled trial]/lim.

\section{Study selection criteria and quality assessment}

Eligible studies were selected based on the following criteria: randomized controlled study design; patient age 18-75 years; LDL cholesterol levels $\geq 130 \mathrm{mg} / \mathrm{dL}$ and triglyceride levels $\leq 600 \mathrm{mg} / \mathrm{dL}$; and intervention consisting of pitavastatin versus simvastatin. The two authors independently conducted the study selection based on these criteria. Any discrepancy was resolved by discussion and the consent of both authors. The quality of the included trials was assessed using the Jadad scale score ( 0 to 5 ), including method of randomization, use of controls, and a description of withdrawals and dropouts, with a score of $\geq 3$ indicating high quality. ${ }^{16}$

\section{Primary and secondary outcomes}

The primary outcome for assessment of statin efficacy was the percent change in LDL cholesterol concentrations compared with baseline. Secondary outcomes included the percent change in total cholesterol, triglyceride, and high-density lipoprotein (HDL) cholesterol concentrations compared with baseline.

\section{Data extraction and statistical analysis}

The following information was extracted from the selected studies: author, publication year, study design, number of patients analyzed, treatment regimen, and primary and secondary outcomes. All statistical analyses were performed using
Review Manager version 5.1.0 (Cochrane Collaboration, Oxford, UK). Continuous outcomes are presented as the mean difference with a 95\% confidence interval. Heterogeneity across trials was also evaluated. A $P$-value $<0.05$ was considered to be statistically significant. Random-effects models were used for meta-analysis if heterogeneity was statistically significant; otherwise, fixed-effects models were applied. Outcomes that could not be pooled for meta-analysis are summarized in Table 1.

\section{Results}

\section{Study identification and characteristics}

A total of 81 unique records were identified by our search strategy. After initial screening by title and abstract, four relevant studies were selected for full text retrieval (Figure 1). ${ }^{9-12}$ Among these studies, 908 patients treated with pitavastatin 2 or $4 \mathrm{mg} /$ day and 381 patients treated with simvastatin 20 or $40 \mathrm{mg}$ /day were included in the final statistical analysis. Two papers presented data from the same study, which consisted of a 12-week initial treatment period (the core study) ${ }^{9}$ followed by a 44 -week extension. ${ }^{10}$ Jadad scores were high $(>3)$ for these studies except for one (Jadad score 2) which was open-label. ${ }^{13}$ Study characteristics and quality assessment are summarized in Table 1.

\section{Publication bias assessment}

A Begg's funnel plot was used for assessment of publication bias in the studies selected for meta-analysis. No publication bias was detected (Figure 2).

\section{Percent change in LDL cholesterol concentrations compared with baseline}

Data with standard deviations were pooled and subjected to meta-analysis. Eriksson et al and Ose et al presented qualified data on percent change in LDL cholesterol concentrations compared with baseline after 12 weeks of treatment with pitavastatin $4 \mathrm{mg}$ or simvastatin $40 \mathrm{mg} .{ }^{9-11}$ A total of 552 patients treated with pitavastatin and 228 treated with simvastatin were included in the final analysis. No statistically significant difference was identified between pitavastatin and simvastatin (mean difference $-0.66 ; 95 \%$ confidence interval $-2.92,1.61 ; P=0.57)$. Ericksson et al and Park et al presented meta-analyses that qualified data on percent change in LDL cholesterol concentrations compared with baseline after 4 weeks of treatment with pitavastatin $2 \mathrm{mg}$ and simvastatin $20 \mathrm{mg} .{ }^{9,12}$ A total of 282 patients treated with pitavastatin and 164 treated with simvastatin were included in the final analysis. Simvastatin $20 \mathrm{mg}$ showed a 


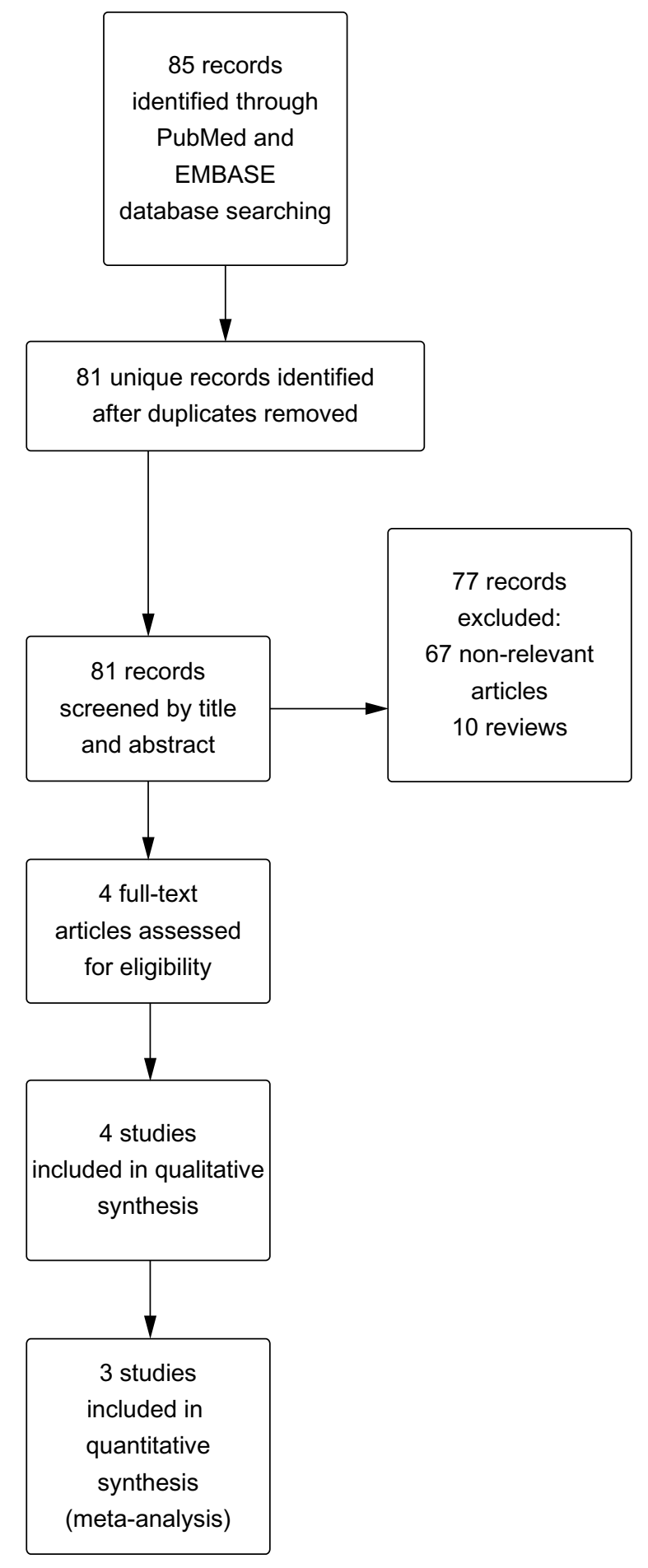

Figure I Flow diagram of study selection.

trend towards higher efficacy in lowering LDL cholesterol concentrations as compared with pitavastatin $2 \mathrm{mg}$, although the difference did not reach statistical significance (mean difference $2.19 ; 95 \%$ confidence interval $-0.11,4.49 ; P=0.06$ ). No heterogeneity was identified within these studies and a fixed-effects model was applied for the meta-analysis (Figure 3).
Ose et al also presented data on percent change in LDL cholesterol concentrations after 12 weeks of treatment with pitavastatin $2 \mathrm{mg}(\mathrm{n}=307)$ and simvastatin $20 \mathrm{mg}$ $(n=107) .{ }^{11}$ Treatment with pitavastatin was more effective in lowering LDL cholesterol concentrations versus treatment with simvastatin (mean difference 4.1; 95\% confidence interval $0.8,7.3 ; P=0.014$ ). However, Park et al found no statistically significant difference in percent change in LDL cholesterol concentrations after 8 weeks of treatment with pitavastatin $2 \mathrm{mg}(\mathrm{n}=49)$ or simvastatin $20 \mathrm{mg},(\mathrm{n}=46 ; P=0.684){ }^{12}$

The long-term effects of statins (44 weeks) on percent change in LDL cholesterol concentrations compared with baseline were only presented in the study by Ericksson et al. ${ }^{10}$ Similar effects were observed for pitavastatin $4 \mathrm{mg}(\mathrm{n}=120)$ and simvastatin $40 \mathrm{mg}(\mathrm{n}=57 ;-41.81 \pm 15.1$ versus $-41.37 \pm 16.4$, respectively).

\section{Secondary outcomes}

Secondary outcomes in the four studies included percent change in total cholesterol, triglyceride, and HDL cholesterol concentrations compared with baseline. Pitavastatin was more effective in lowering total cholesterol $(2 \mathrm{mg}$, 12 weeks) and triglycerides (4 mg, 12 weeks) as compared with simvastatin (20 and $40 \mathrm{mg}, 12$ weeks; total cholesterol, $P=0.041$; triglycerides, $P=0.044) .{ }^{8,10}$ No statistically significant differences were observed in other secondary outcomes between pitavastatin and simvastatin. Secondary outcome data are summarized in Table 2.

\section{Discussion}

Our meta-analysis and systemic review confirms the conclusion from previous multiple individual clinical studies that long-term treatment with pitavastatin ( $>12$ weeks) at a dose of $4 \mathrm{mg} /$ day is noninferior to simvastatin in lowering LDL cholesterol concentrations. Whereas short-term treatment with pitavastatin (4 weeks) at a low dose ( $2 \mathrm{mg}$ /day) showed a trend towards lower efficacy as compared with simvastatin $(P=0.06)$, long-term treatment with pitavastatin (12 weeks) was more effective $(P=0.014){ }^{11}$

Long-term safety is an important concern when using a statin. A 44-week extension study showed that treatmentemergent adverse events (TEAEs) were similar between pitavastatin $4 \mathrm{mg} /$ day and simvastatin $40 \mathrm{mg} /$ day $(13 \%$ versus $10 \%$, respectively). ${ }^{9}$ Most of these TEAEs were mild or moderate in severity. Moreover, the adverse events profiles of pitavastatin and simvastatin were similar, and dose-related TEAEs were not observed. ${ }^{11}$ These results demonstrate that 


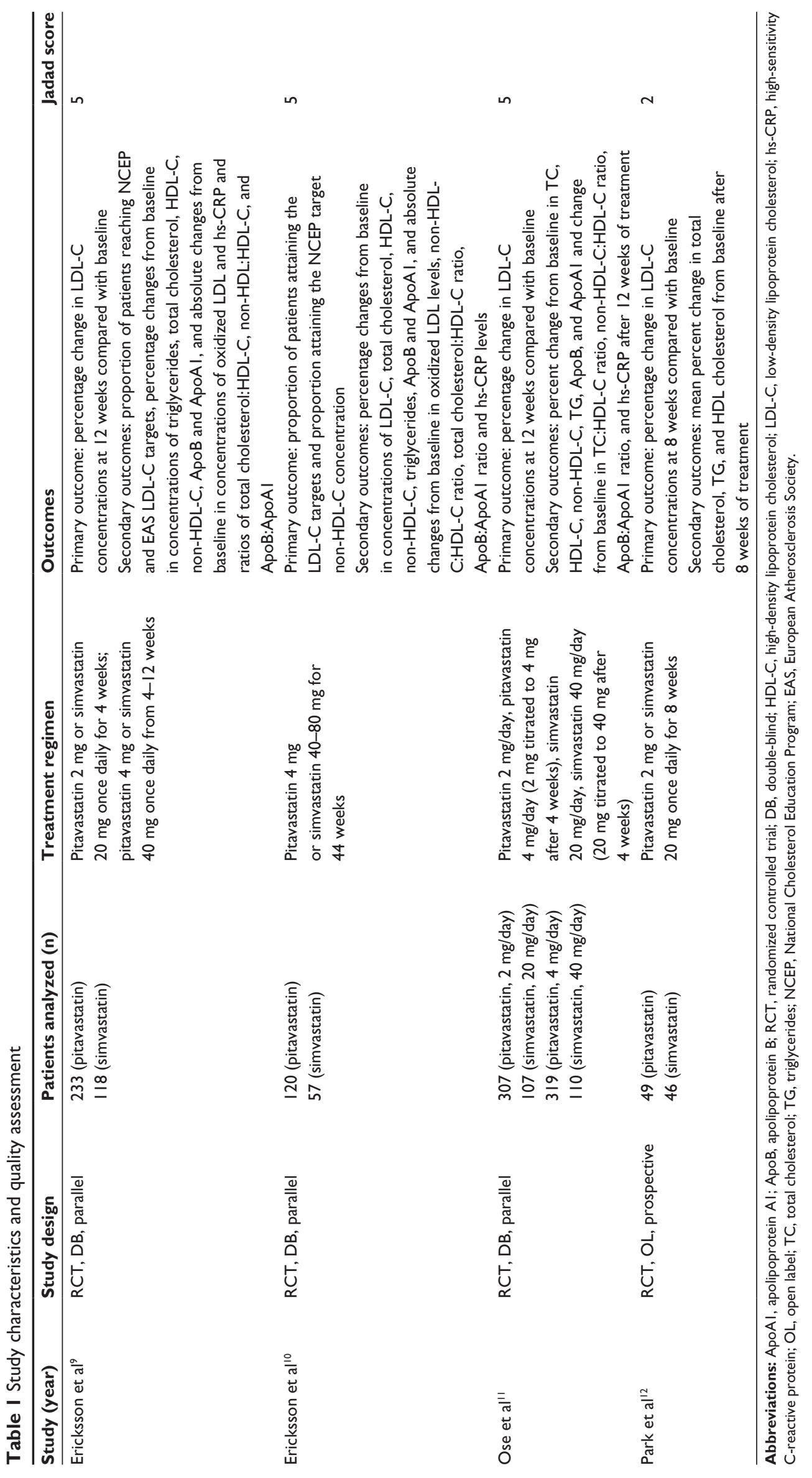




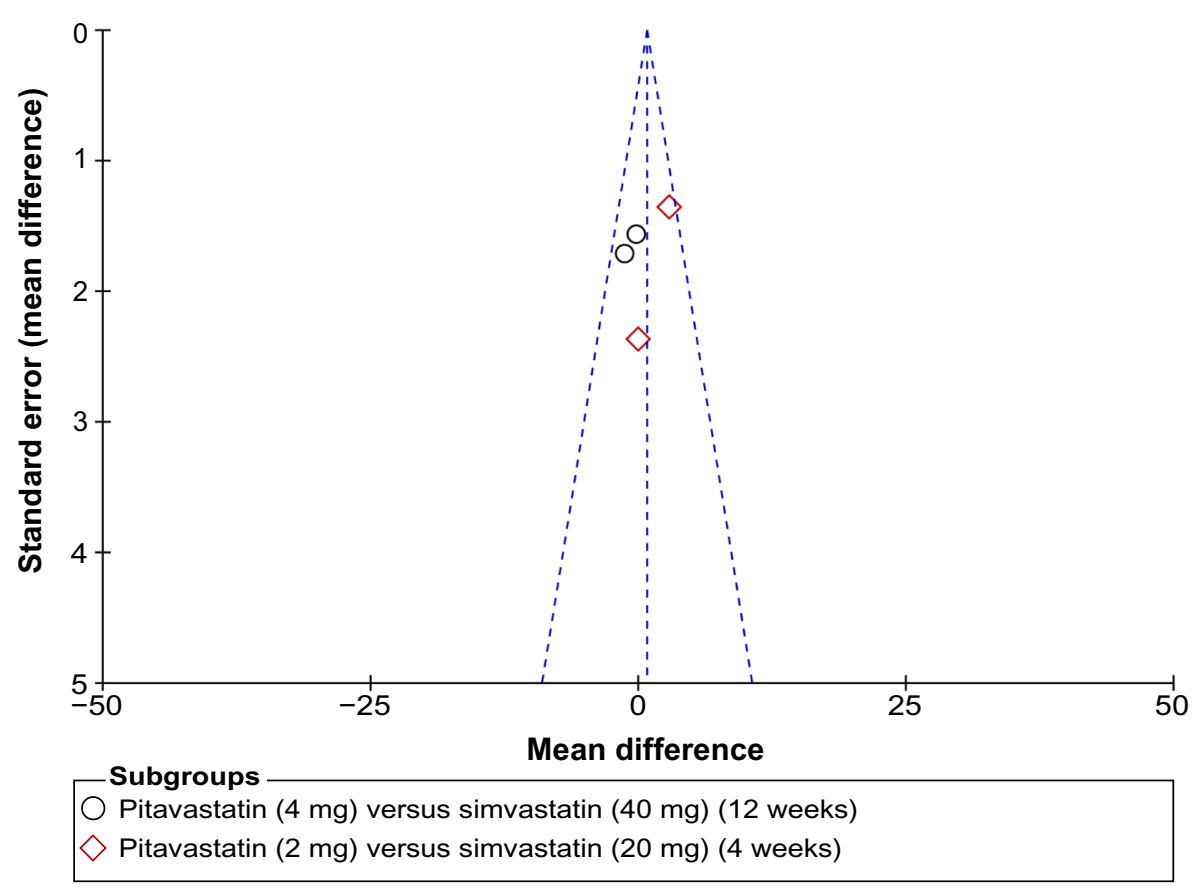

Figure 2 Funnel plot of the studies selected. The plot is for qualitative estimation of publication bias of the studies. No bias was found.

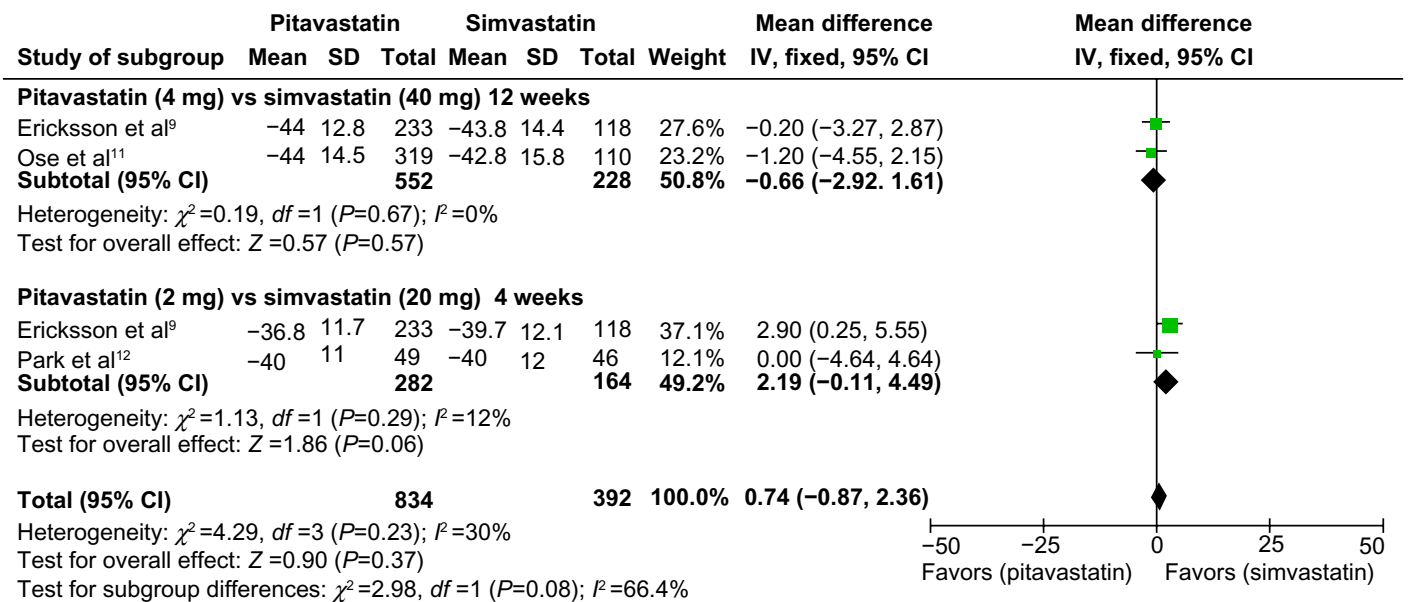

Figure 3 Forest plot of mean difference comparing percentage change in low-density lipoprotein cholesterol concentrations between pitavastatin and simvastatin treatment. Abbreviations: $\mathrm{Cl}$, confidence interval; IV, inverse variance; SD, standard deviation.

Table 2 Mean percentage of changes in secondary outcomes from baseline

\begin{tabular}{|c|c|c|c|c|c|c|c|c|}
\hline Outcomes & $\begin{array}{l}\text { Pitavastatin } \\
(2 \mathrm{mg} / \text { day, } \\
8 \text { weeks }) \\
\text { Park et } \text { al }^{12}\end{array}$ & $\begin{array}{l}\text { Simvastatin } \\
(20 \text { mg/day, } \\
8 \text { weeks }) \\
\text { Park et al }{ }^{12}\end{array}$ & $\begin{array}{l}\text { Pitavastatin } \\
\text { (2 mg/day, } \\
\text { I2 weeks) } \\
\text { Ose et al" }\end{array}$ & $\begin{array}{l}\text { Simvastatin } \\
\text { ( } 20 \text { mg/day, } \\
\text { I } 2 \text { weeks) } \\
\text { Ose et al" }\end{array}$ & $\begin{array}{l}\text { Pitavastatin } \\
(4 \mathrm{mg} / \text { day }) \\
\text { Eriksson et } \mathrm{al}^{9,10}\end{array}$ & $\begin{array}{l}\text { Simvastatin } \\
(40 \mathrm{mg} / \text { day }) \\
\text { Eriksson et } \mathrm{al}^{9,10}\end{array}$ & $\begin{array}{l}\text { Pitavastatin } \\
\text { ( } 4 \text { mg/day, } \\
\text { I } 2 \text { weeks) } \\
\text { Ose et al" }\end{array}$ & $\begin{array}{l}\text { Simvastatin } \\
\text { (40 mg/day, } \\
12 \text { weeks) } \\
\text { Ose et al" }\end{array}$ \\
\hline $\mathrm{TC}$ & -26.9 & -28.5 & -27.9 & -25.4 & -31.4 (12 weeks) & -31.2 (I2 weeks) & -31.5 & -30.5 \\
\hline$P$-value & 0.405 & & $0.04 I$ & & $\begin{array}{l}-27.4 \text { (44 weeks) } \\
0.793 \text { (12 weeks) }\end{array}$ & -27.6 (44 weeks) & 0.479 & \\
\hline TG & -29.8 & -17.4 & -15.9 & -15.6 & -19.8 (12 weeks) & -14.8 (I2 weeks) & -16.8 & -16.1 \\
\hline$P$-value & 0.147 & & 0.822 & & $\begin{array}{l}-11.5 \text { (44 weeks) } \\
0.044 \text { (12 weeks) }\end{array}$ & -12.3 (44 weeks) & 0.866 & \\
\hline HDL-C & 8.3 & 3.6 & 6.0 & 5.5 & 6.8 (I2 weeks) & 4.5 (I2 weeks) & 6.2 & 6.8 \\
\hline$P$-value & 0.127 & & 0.782 & & $\begin{array}{l}\text { I4.I ( } 44 \text { weeks) } \\
0.083 \text { (I2 weeks) }\end{array}$ & I 4.6 (44 weeks) & 0.791 & \\
\hline
\end{tabular}

Abbreviations: TC, total cholesterol; TG, triglycerides; HDL-C, high-density lipoprotein cholesterol. 
pitavastatin is well tolerated in long-term treatment, even at high doses.

Our meta-analysis has two limitations. First, no drugdrug interaction data were available in the selected studies. In clinical practice, simvastatin is the most widely used statin for lowering LDL cholesterol. ${ }^{17}$ However, like most statins, simvastatin is metabolized by hepatic cytochrome P450 enzymes, so has an increased potential for serious side effects through drug interactions. ${ }^{18}$ Pitavastatin is a promising alternative to simvastatin for lowering LDL cholesterol, given its unique feature of being virtually unmetabolized by the cytochrome P450 family. However, no clinical studies are currently available to investigate the drug interactions of pitavastatin as compared with other statins. Second, the total number of patients in these studies is small, so care should be taken when using our results to guide treatment of patients with hypercholesterolemia. In conclusion, pitavastatin is noninferior to simvastatin in lowering LDL cholesterol.

\section{Disclosure}

The authors report no conflicts of interest in this work.

\section{References}

1. World Health Organization. Cardiovascular diseases - Fact sheet 317. Available from: http://www.who.int/mediacentre/factsheets/fs317/en/. Accessed May 8, 2014.

2. Catapano AL, Reiner Z, De Backer G, et al. ESC/EAS Guidelines for the management of dyslipidaemias: The Task Force for the management of dyslipidaemias of the European Society of Cardiology (ESC) and the European Atherosclerosis Society (EAS). Atherosclerosis. 2011;217: 3-46.

3. Baigent C, Blackwell L, Emberson J, et al; for the Cholesterol Treatment Trialists' (CTT) Collaboration. Efficacy and safety of more intensive lowering of LDL cholesterol: a meta-analysis of data from 170,000 participants in 26 randomised trials. Lancet. 2010;376: $1670-1681$.

4. Reiner Z. Statins in the primary prevention of cardiovascular disease. Nat Rev Cardiol. 2013;10:453-464.
5. Chatzizisis YS, Koskinas KC, Misirli G, Vaklavas C, Hatzitolios A, Giannoglou GD. Risk factors and drug interactions predisposing to statin-induced myopathy: implications for risk assessment, prevention and treatment. Drug Saf. 2010;33:171-187.

6. Duggan ST. Pitavastatin: a review of its use in the management of hypercholesterolaemia or mixed dyslipidaemia. Drugs. 2012;72: $565-584$.

7. Teramoto T. The clinical impact of pitavastatin: comparative studies with other statins on LDL-C and HDL-C. Expert Opin Pharmacother. 2012;13:859-865.

8. Corsini A, Ceska R. Drug-drug interactions with statins: will pitavastatin overcome the statins' Achilles' heel? Curr Med Res Opin. 2011;27:1551-1562.

9. Eriksson M, Budinski D, Hounslow N. Comparative efficacy of pitavastatin and simvastatin in high-risk patients: a randomized controlled trial. Adv Ther. 2011;28:811-823.

10. Eriksson M, Budinski D, Hounslow N. Long-term efficacy of pitavastatin versus simvastatin. Adv Ther. 2011;28:799-810.

11. Ose L, Budinski D, Hounslow N, Arneson V. Comparison of pitavastatin with simvastatin in primary hypercholesterolaemia or combined dyslipidaemia. Curr Med Res Opin. 2009;25:2755-2764.

12. Park S, Kang HJ, Rim SJ, et al. A randomized, open-label study to evaluate the efficacy and safety of pitavastatin compared with simvastatin in Korean patients with hypercholesterolemia. Clin Ther. 2005;27: 1074-1082.

13. Lee SH, Chung N, Kwan J, et al. Comparison of the efficacy and tolerability of pitavastatin and atorvastatin: an 8-week, multicenter, randomized, open-label, dose-titration study in Korean patients with hypercholesterolemia. Clin Ther. 2007;29:2365-2373.

14. Sansanayudh N, Wongwiwatthananukit S, Putwai P, Dhumma-Upakorn R. Comparative efficacy and safety of low-dose pitavastatin versus atorvastatin in patients with hypercholesterolemia. Ann Pharmacother. 2010;44:415-423.

15. Sasaki J, Ikeda Y, Kuribayashi T, et al. A 52-week, randomized, open-label, parallel-group comparison of the tolerability and effects of pitavastatin and atorvastatin on high-density lipoprotein cholesterol levels and glucose metabolism in Japanese patients with elevated levels of low-density lipoprotein cholesterol and glucose intolerance. Clin Ther. 2008;30:1089-1101.

16. Jadad AR, Moore RA, Carroll D, et al. Assessing the quality of reports of randomized clinical trials: is blinding necessary? Control Clin Trials. 1996;17:1-12.

17. Kolovou GD, Katerina A, Ioannis V, Cokkinos DV. Simvastatin: two decades in a circle. Cardiovasc Ther. 2008;26:166-178.

18. Florentin M, Elisaf MS. Simvastatin interactions with other drugs. Expert Opin Drug Saf. 2012;11:439-444.
Drug Design, Development and Therapy

\section{Publish your work in this journal}

Drug Design, Development and Therapy is an international, peerreviewed open-access journal that spans the spectrum of drug design and development through to clinical applications. Clinical outcomes, patient safety, and programs for the development and effective, safe, and sustained use of medicines are a feature of the journal, which

\section{Dovepress}

has also been accepted for indexing on PubMed Central. The manuscript management system is completely online and includes a very quick and fair peer-review system, which is all easy to use. Visit http://www.dovepress.com/testimonials.php to read real quotes from published authors. 